\title{
A REGIÃO TRANSFRONTEIRIÇA DO IGUAÇU E AS AÇÕES DA IIRSA
}

\author{
The Iguaçu Cross-Border Region and IIRSA's actions
}

\section{La Región Transfronteriza de Iguazú y las acciones de IIRSA}

\author{
Francisco Jorge Vicente* \\ Aldomar Arnaldo Rückert ** \\ * Mestre em Estudos Estratégicos Internacionais e Doutorando em Geografia, UFRGS \\ E-mail: chicojvicente@gmail.com \\ ** Professor Titular no Departamento de Geografia da UFRGS \\ E-mail: aldomar.ruckert@gmail.com
}

Recebido em 01/10/2020. Aceito para publicação em 16/11/2020.

Versão online publicada em 24/11/2020 (http://seer.ufrgs.br/paraonde)

\section{RESUMO}

Relações transfronteiriças implicam em processos que podem ou não evoluir para a conformação de regiões transfronteiriças. A Bacia do Prata, por suas condições históricas, econômicas e geográficas, é uma região propensa a desenvolver este tipo de formação socio-geográfica, o que explica em seu interior, a existência de 24 cidades-gêmeas, das 33 reconhecidas pelo Brasil. $\mathrm{Na}$ região da Tríplice Fronteira entre Argentina, Brasil e Paraguai, se desenvolve a embrionária, e ainda informal, Região Transfronteiriça do Iguaçu, em torno das cidades tri-gêmeas de Puerto Iguazú, Foz do Iguaçu e Ciudad del Este. As ações de integração da infraestrutura regional da IIRSA desenvolvidas por atores territoriais multiescalares estão estimulando este processo de transfronteirização e provocando importantes consequências políticas, econômicas, sociais e ambientais nesta região da fronteira e, em especial, para as cidades tri-gêmeas envolvidas neste processo.

Palavras-chave: região transfronteiriça. cidades tri-gêmeas. Bacia do Prata. UNASUL. IIRSA.

\begin{abstract}
Cross-border relations imply processes that may or may not evolve into crossborder regions. The La Plata Basin, due to its historical, economic and geographical conditions, is a region prone to develop this type of sociogeographic formation, which explains in its interior, the existence of 24 twin cities, of the 33 recognized by Brazil. In the Triple Border region between Argentina, Brazil and Paraguay, the embryonic, yet informal Iguaçu Cross-Border Region develops around the triple twin cities of Puerto Iguazu, Foz do Iguaçu and Ciudad del Este. IIRSA's regional infrastructure integration actions carried out by multiscale territorial actors are stimulating this cross-border process and causing important political, economic, social and environmental consequences in this border region and, in particular, for the triple twin cities involved in this process.
\end{abstract}

Keywords: cross-border region. triple twin cities. La Plata Basin. UNASUL. IIRSA. 


\begin{abstract}
RESUMEN
Las relaciones transfronterizas implican procesos que pueden o no evolucionar para la conformación de regiones transfronterizas. La Cuenca del Plata, debido a sus condiciones históricas, económicas y geográficas, es una región propensa a desarrollar este tipo de formación sociogeográfica, lo que explica en su interior la existencia de 24 ciudades gemelas, de las 33 reconocidas por Brasil. En la región de la Triple Frontera entre Argentina, Brasil y Paraguay, la región transfronteriza embrionaria, y aún informal, de Iguazú se desarrolla alrededor de las triple ciudades gemelas de Puerto Iguazú, Foz do Iguaçu y Ciudad del Este. Las acciones de integración de Infraestructura regional de IIRSA llevadas a cabo por actores territoriales multiescalares están estimulando este proceso transfronterizo y causando importantes consecuencias políticas, económicas, sociales y ambientales en esta región fronteriza y, en particular, para las triple ciudades gemelas involucradas en este proceso.
\end{abstract}

Palabras clave: región transfronteriza. triple ciudades gemelas. Cuenca del Plata. UNASUR. IIRSA.

\title{
1. Introdução
}

As inúmeras conexões pessoais, políticas, econômicas, culturais entre atores territoriais de distintos países podem estabelecer relações transfronteiriças. Entretanto, em função de sua pertinência, profundidade, frequência, escala, caráter e outras características, essas relações podem ou não evoluir para processos de transfronteirização. Quando estas múltiplas relações se tornam intensas, recíprocas e cotidianas, institucionalizando conexões entre atores de países diversos numa determinada região fronteiriça, pode-se estar diante de uma região transfronteiriça.

Estas regiões comumente se formam em zonas de fronteira contíguas de dois ou mais territórios nacionais, mas podem estabelecer vínculos locais, regionais, supra regionais, nacionais ou mesmo globais. As designadas cidades gêmeas entre fronteiras de dois ou mais países vizinhos são potenciais embriões de relações, processos e regiões transfronteiriças.

O objetivo deste artigo é identificar se as repercussões territoriais das ações movidas por atores territoriais de diversas escalas de poder na embrionária Região Transfronteiriça do Iguaçu (RTI) e, em especial, aquelas realizadas pela Iniciativa para a Integração da Infraestrutura Regional Sul-Americana (IIRSA), programa da União de Nações Sul-Americanas (UNASUL), estão contribuindo para o desenvolvimento da nascente RTI.

Foram identificados 13 projetos de infraestrutura da IIRSA na área da RTI que priorizam setores condicionados aos cursos de rios e à presença da Itaipu Binacional na região, fazendo com que a matriz de projetos ali seja diferente do conjunto da carteira da IIRSA, com prioridade para os setores hidroviário e energético. A construção da segunda ponte ligando Brasil e Paraguai poderá potencializar o processo de transfronteirização.

O artigo contém, além da introdução e das considerações finais, outras quatro partes. Na primeira, o objetivo é contribuir com o debate acerca das concepções de fronteira, processos de transfronteirização, cidades gêmeas e regiões transfronteiriças.

Na segunda parte, objetiva-se identificar as razões históricas, espaciais e

ParaOnde!?, Porto Alegre, v.14, n.1, p.71-89, 2020.http://seer.ufrgs.br/paraonde 
econômicas que fazem da Bacia do Prata uma região propícia ao surgimento de processos transfronteiriços que poderão evoluir ou não para regiões transfronteiriças, tal como está ocorrendo com a nascente RTI, bem como, delimitar sua espacialidade e suas principais características.

$\mathrm{Na}$ terceira e quarta partes, pretende-se estudar algumas repercussões territoriais das ações da IIRSA que cruzam ou se situam na RTI, verificando-se os impactos das ações já concluídas e em andamento, além das projeções de ações futuras já indicadas na carteira de projetos, bem como as características e os interesses explícitos de grandes atores que operam estas ações na citada região.

\section{Discutindo fronteiras, cidades gêmeas, processos de transfronteirização e regiões transfronteiriças}

O conceito de fronteira "nasceu como um fenômeno da vida social espontânea, indicando a margem do mundo habitado", evoluindo, com o desenvolvimento dos padrões de civilização, para lugares de comunicação, adquirindo, assim, um caráter político. "Na verdade, o sentido de fronteira não era de fim, mas do começo do Estado, o lugar para onde ele tendia a se expandir. A palavra limite, de origem latina, foi criada para designar o fim daquilo que mantém coesa uma unidade político-territorial, ou seja, sua ligação interna" (MACHADO, 1998, p.41). Esta conotação política foi reforçada a partir do conceito moderno de Estado, ao final da Guerra dos Trinta Anos, em 1648, onde território e fronteira nacional passaram a corresponder a um processo absoluto de soberania.

Da criação do Estado-nação, no Século XVII, através dos Tratados de Westphalia, até o fim da Guerra Fria, nos anos 1980, as fronteiras serviram, com raras exceções, para conter e controlar fluxos e determinar o exercício do poder territorial. Porém, ainda nos anos 1950, com os primeiros passos da futura União Europeia (UE), os fundamentos deste conceito de fronteira começaram a sofrer abalos. Os processos de integração regional, intensificados pelos movimentos da globalização, transformaram as fronteiras em espaços fluidos, dinâmicos, porosos, complexos e ambivalentes.

Dizem Amilhat Szary e Giraut (2015) que, a contrassenso do que era esperado, com o progresso tecnológico dos anos 1990, com a proliferação da internet e das comunicações móveis, bem como a intensificação dos fluxos comerciais e financeiros com regulações mais abrandadas, ao invés de se universalizarem, a abertura de fronteiras resultaram, em todos os lugares e ao mesmo tempo, na construção de novas muralhas, em concomitantes processos de "debordering/rebordering" - (relaxamento/soerguimento de fronteiras), discriminando e selecionando pessoas, bens, capitais e informações, desejáveis ou indesejáveis, tornando suas funções ainda mais difusas.

Estas características recentes colocam a fronteira não mais nas margens do Estado, mas no centro das ações das políticas estatais (BALIBAR, 1996). Tudo isto indica a necessidade de se analisar a fronteira de forma distinta, levando-se mais em consideração as espacialidades fronteiriças do que a fronteirização em si e as linhas de fronteiras.

ParaOnde!?, Porto Alegre, v.14, n.1, p.71-89, 2020.http://seer.ufrgs.br/paraonde 
Pensar a complexa realidade das fronteiras exige considerar as diferentes funcionalidades que são hoje atribuídas pelo capital e pela sociedade às cidades gêmeas, para além dos seus papéis de conexão e controle entre países fronteiriços (CAMPOS, 2017). Impõem-se analisar seu caráter binacional que atrai pessoas de todos os lugares por constituir um meio cosmopolita, de fácil adaptação a qualquer estrangeiro. As cidades gêmeas, em geral, possibilitam uma convivência transfronteiriça, enriquecida pela heterogeneidade cultural e étnica, possibilitando a articulação de redes de diversos tipos e origens (MACHADO, 2010). Por isto, as cidades gêmeas são embriões de processos e de regiões transfronteiriças.

Na América do Sul existem dezenas de cidades gêmeas - cidades vizinhas destacadas por uma linha de fronteira nacional, das mais diversas formas e tamanhos nas fronteiras de praticamente todos os países. O Brasil reconhece 33 cidades gêmeas com 11 países sul-americanos e destas, 24 se encontram na região da Bacia do Prata. Com o Equador e o Chile, o Brasil não tem fronteira física e, dos 10 países restantes, apenas com o Suriname não conta com cidades gêmeas. Condicionantes políticos, históricos e geográficos favoreceram a formação do quadro atual e oferecem condições específicas para o desenvolvimento deste tipo de formação geográfica nesta porção do território sul-americano. Uma das regiões transfronteiriças mais potentes da América do Sul, em termos populacionais, econômicos, de fluxos e de relações que se estendem para além da região específica, é aquela que se localiza na Tríplice Fronteira entre Argentina, Brasil e Paraguai. A foto 1 apresenta dizeres que reportam a identidades comuns e relações de amizade entre esses países.

Foto 1 - Dizeres de amizade entre os povos em Foz do Iguaçu.

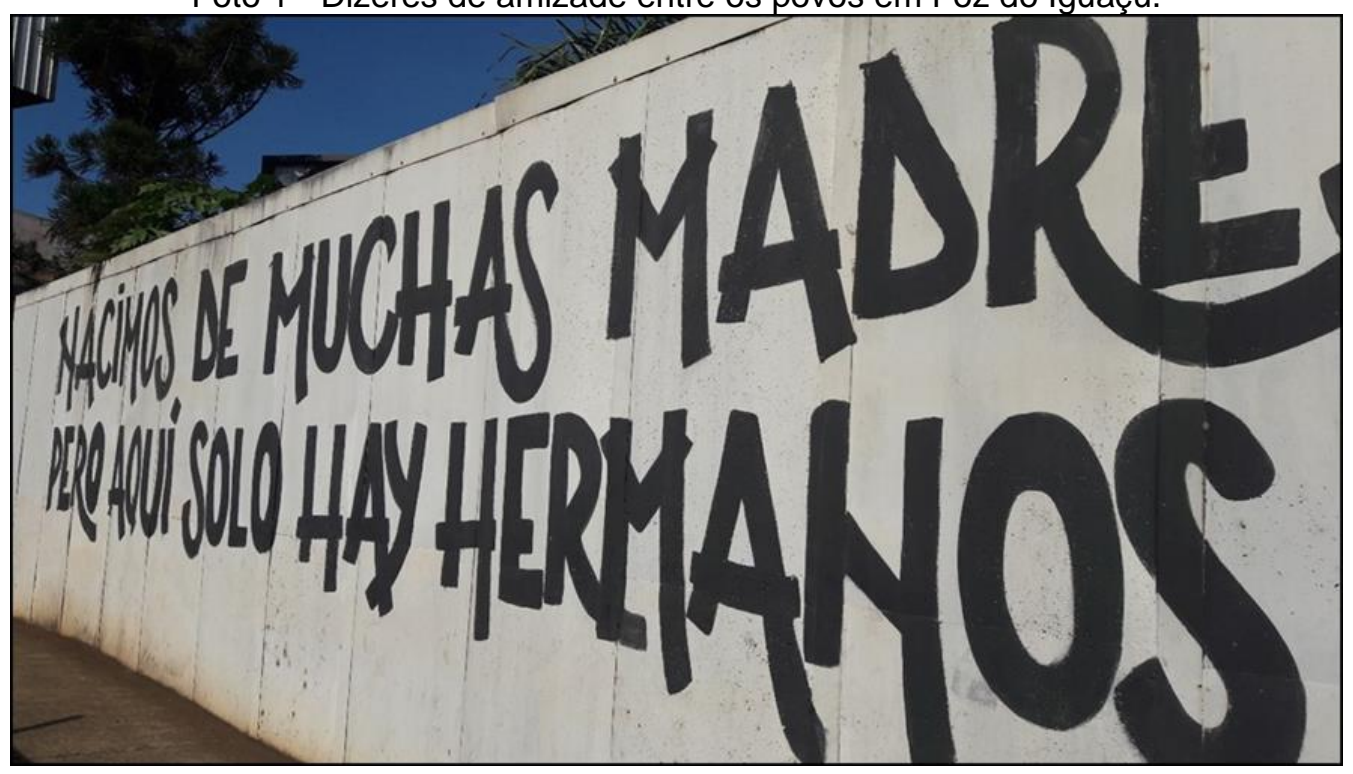

Fonte: Aldomar Arnaldo Rückert, 2018.

A RTI constitui uma área com elevada densidade técnica e com uma enorme dimensão e intensidade de variação de fluxos, o que para França (2016, p. 119) exige que a pensemos a partir de, ao menos, três escalas geográficas: "a fronteira geopolítica (Estado e relações internacionais), a fronteira da fluidez (da grande mobilidade de capital e trabalho) e a fronteira como lugar (o espaço do cotidiano)".

ParaOnde!?, Porto Alegre, v.14, n.1, p.71-89, 2020.http://seer.ufrgs.br/paraonde 
Nesta região são intensas as relações e os processos transfronteiriços entre inúmeros atores que estabelecem cotidianamente entre si fluxos e relações comerciais, turísticas, culturais, políticas, ilícitas, institucionais, dentre várias outras, o que levou Rückert, et al. (2014) a afirmarem que a alta densidade de atores trinacionais ali concentrados e suas intensas relações e processos estão criando uma nova transfronteirização.

Entretanto, mesmo contendo os atributos suficientes e necessários, em comparação com o que ocorre na Europa, a embrionária RTI, é apenas uma região de fato, por não haver na América do Sul, uma definição normativa sobre o tema. A Europa, com seu processo de integração regional, acelerou estas formações sócio-geográficas por meio de diversos instrumentos de políticas territoriais, em especial, através da criação do INTERREG, em 1990, um programa de apoio à cooperação transfronteiriça que agrega um conjunto de organismos e ações no âmbito das políticas de fronteiras no território europeu. Hoje, regiões transfronteiriças, tais como, a Região Metropolitana Trinacional do Reno Superior, a Euro-região Galícia-Norte de Portugal e a Grande Región que abarca porções dos territórios da Alemanha, França, Bélgica e a totalidade de Luxemburgo, dentre várias outras, são institucionalmente reconhecidas e recebem apoio para desenvolver ações com vistas à redução das assimetrias, ao desenvolvimento da região, ao fomento da cooperação transfronteiriça e à criação de ambientes de convívio saudáveis e plurais entre seus habitantes (WASSENBERG e REITEL, 2015).

Estas breves considerações preliminares demonstram que é nos limites dos territórios nacionais, geralmente em torno de cidades gêmeas, que estes processos de transfronteirização encontram um ambiente mais favorável para se tornarem regiões transfronteiriças. A região da Bacia do Prata e a RTI parecem corroborar esta afirmação com os elementos que serão apresentados na sequência deste artigo.

\section{A Bacia do Prata e a Região Transfronteiriça do Iguaçu}

Por se localizar no coração ou heartland do subcontinente sul-americano, a Bacia do Prata sempre foi palco de disputas geopolíticas, destacando-se a Guerra do Paraguai e a rivalidade recém superada entre Argentina e Brasil que perdurou por séculos. Além do posicionamento geoestratégico, os recursos hídricos, os extensos campos de pastagens, a abundância de terras agricultáveis, as rotas de navegação e a presença de depósitos minerais animavam as disputas. No Mapa 1 pode-se observar a abrangência da Bacia do Prata, bem como suas vias naturais de penetração formadas pelos rios Paraná, Paraguai e Uruguai, contendo em seu centro geográfico a Tríplice Fronteira e nela, a RTI.

Conforme Rappoport e Madrid (1998), em meados do Século XIX, a expansão da produção industrial no Reino Unido, trouxe capitais excedentes para a região criando especializações na exportação de cereais, carnes, couros e lã. No final do século XIX, estes capitais foram canalizados para ferrovias, títulos externos, serviços públicos, setor financeiro, frigoríficos e empresas agropecuárias. Ao final da Segunda Guerra Mundial, os Estados Unidos (EUA) se aproveitaram da nova conjuntura para capturar mercados ingleses na Bacia

ParaOnde!?, Porto Alegre, v.14, n.1, p.71-89, 2020.http://seer.ufrgs.br/paraonde 
do Prata, passando da condição de devedor a credor. A Guerra Fria instituiu aos países da região uma nova condição geopolítica de atrelamento aos EUA, abrindo uma nova dinâmica econômica com investimentos na siderurgia, petroquímica, produção de eletricidade e indústria automobilística.

Foz do Iguaçu passou a ter um incremento econômico, turístico e demográfico com a abertura da Ponte da Amizade ligando Brasil e Paraguai, em 1965 e, com ela, se intensificou a logística, o tráfico de drogas e o contrabando de armas. Entretanto, foi a partir do início da construção da Usina de Itaipu, em 1975, que a cidade teve um salto populacional passando de 33.966 habitantes, em 1970, para 136.352, em 1980 chegando a 256.088 habitantes no ano de 2010 (PAIVA, 2014, p.15). De acordo com o IBGE, em 2019, sua população era estimada em 258.532 pessoas. Com a geração de energia por Itaipu, a participação da indústria no PIB de Foz do Iguaçu, saltou de 9,17\%, em 1970, para os atuais $58,05 \%$, enquanto a participação dos serviços, incluindo turismo e administração pública, caiu de $81,72 \%$ para $33,75 \%$, no mesmo período (PAIVA, 2014,p. 25).

\section{Mapa 1 - Localização da Bacia do Prata e da Tríplice Fronteira Argentina-Brasil-Paraguai}

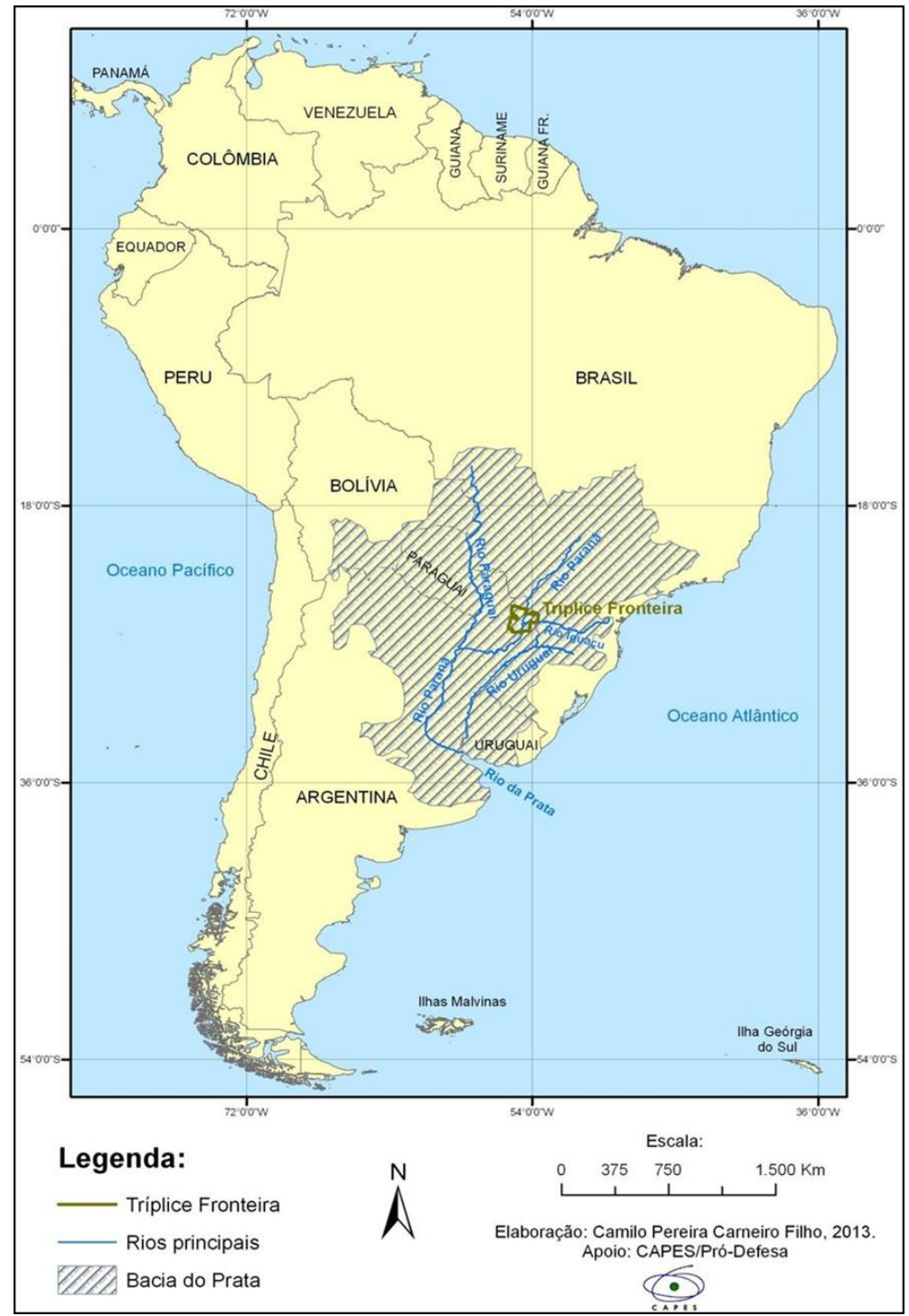

Fonte: CARNEIRO FILHO, 2013, p. 27

ParaOnde!?, Porto Alegre, v.14, n.1, p.71-89, 2020.http://seer.ufrgs.br/paraonde 
Estes fatores atraíram milhares de estrangeiros de diversas nacionalidades que lá se estabeleceram, além de uma quantidade enorme de turistas que visitam anualmente a região. De acordo com dados do Instituto Brasileiro de Geografia e Estatística (IBGE), a produção industrial, incluindo a produção de energia, seguida pela logística, pelo turismo e pela agropecuária são, nesta ordem, os setores econômicos dinâmicos de Foz do Iguaçu.

No Mapa 2 pode-se observar a localização da RTI, abrangendo os Departamentos do Alto Paraná, no Paraguai, o Departamento de Iguazú, na Argentina e a Microrregião de Foz do Iguaçu, no Brasil. Para efeito de ajuste de escalas, em função das diferentes grandezas de áreas entre os países analisados, o referido mapa reúne recortes geográficos de amplitudes distintas, na medida em que no Paraguai, o Departamento do Alto Paraná corresponderia ao Estado do Paraná, no Brasil e à Província de Misiones, na Argentina. A Microrregião de Foz do Iguaçu, no Brasil, corresponderia ao Departamento de Iguazú, na Argentina e ambos não teriam correspondentes equivalentes no Paraguai. Para fins comparativos adota-se uma equivalência tomando-se por base a dimensão das microrregiões geográficas do IBGE e seus correspondentes em nível administrativo e tamanho de área nos países vizinhos. (RÜCKERT, 2015).

Com o objetivo de tentar padronizar estas dimensões, a UE criou, em 2003, um padrão de geocódigos chamado NUTS, porém, a complexidade permanece na medida em que cada país adota critérios distintos para a classificação de áreas. Na América do Sul, assim como na UE, as equivalências entre as diferentes divisões político-administrativas são compostas de valores e dimensões territoriais aproximadas.

A Bacia do Prata, com suas condições favoráveis, a Ponte da Amizade e a Usina de Itaipu, permitiram o lançamento das bases de surgimento e crescimento do processo de transfronteirização na RTI. As obras de integração da infraestrutura regional da IIRSA e as ações de integração regional do Mercado Comum do Sul (MERCOSUL) a estão consolidando. É o que se procurará demonstrar, a seguir.

\section{A Iniciativa para a Integração Regional sul-Americana (IIRSA) e a Região Transfronteiriça do Iguaçu}

A IIRSA foi lançada em 2000, durante a I Reunião dos Presidentes de países sul-americanos, em Brasília, através de um documento previamente articulado por organismos internacionais, chamado "Declaração de Brasília" e passou a ser coordenada pelo Conselho Sul-Americano de Infraestrutura e Planejamento (COSIPLAN), a partir de 2011, já inserido no processo de integração regional da UNASUL, que fora criada em 2008.

Com o objetivo de estimular as ações de integração da infraestrutura, especialmente as de logística de transporte, entre os países do subcontinente, a IIRSA se ancorou nas estruturas já construídas e nos projetos previamente elaborados, porém, agora com uma preocupação maior em relação à instalação de corredores transversais de exportação para o escoamento de commodities agrícolas e minerais, ligando os oceanos Atlântico e Pacífico. O enfoque

ParaOnde!?, Porto Alegre, v.14, n.1, p.71-89, 2020.http://seer.ufrgs.br/paraonde 
predominante dos projetos visa a ligação dos centros de produção de matériasprimas com os pontos de transbordo (portos fluviais e marítimos), cruzando o território sem se deter na conformação de mecanismos associados que permitam o fomento ao desenvolvimento regional e à economia local. Grandes empresas extraem os produtos, transportam as mercadorias e as vendem no destino, embora se observe, especialmente no nordeste argentino e no leste paraguaio, uma leve inclinação em sentido diverso, com o estabelecimento de ações que integram o território numa lógica econômica mais preocupada com 0 desenvolvimento regional.

Mapa 2 - Proposta de divisão administrativa da Região Transfronteiriça do Iguaçu

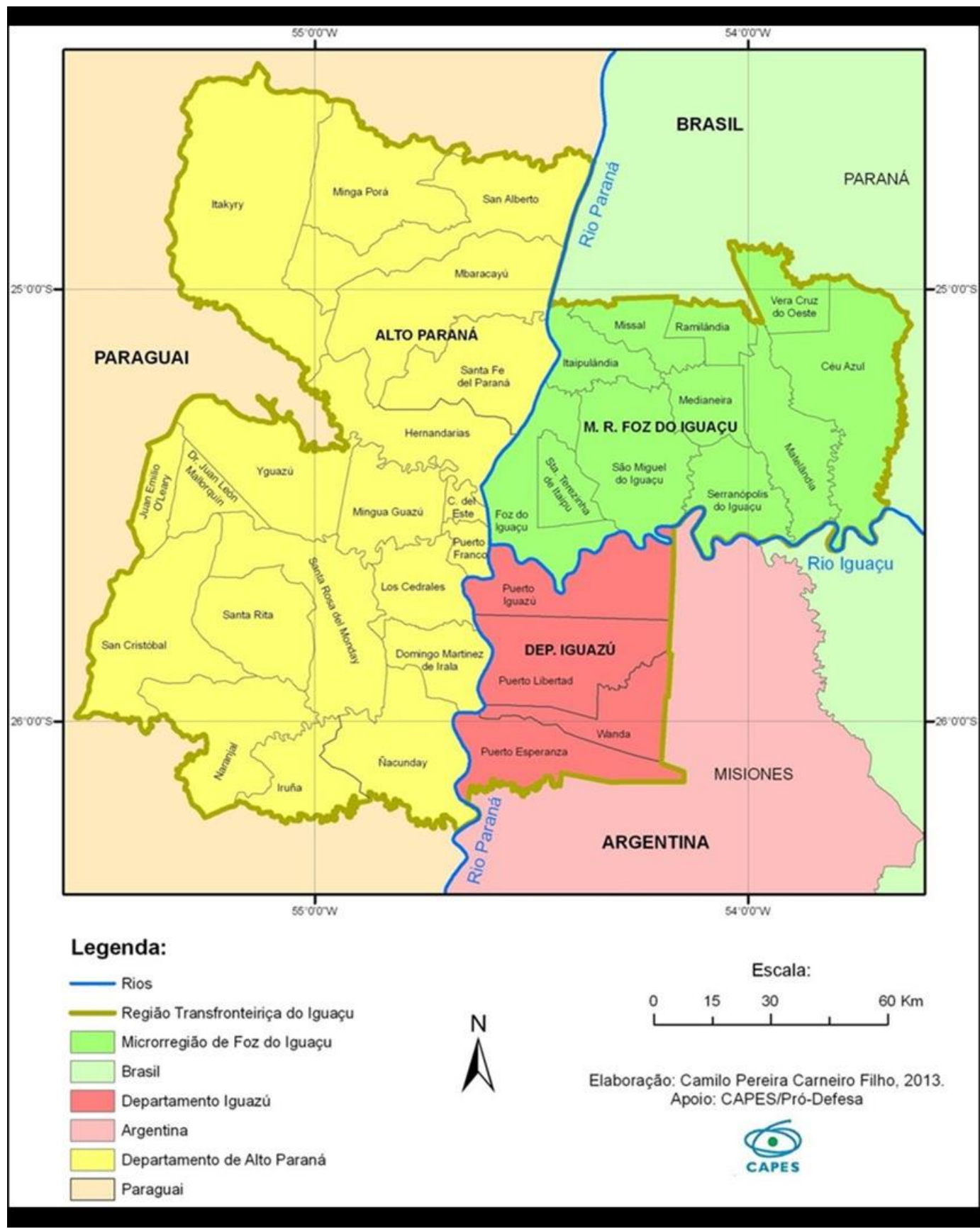

Fonte: CARNEIRO FILHO, 2013, p. 101.

ParaOnde!?, Porto Alegre, v.14, n.1, p.71-89, 2020.http://seer.ufrgs.br/paraonde 
Como as ações da IIRSA se distribuem por todos os países da América do Sul, foram identificados 13 projetos que, de alguma forma, ou se localizam ou cruzam, a Região Transfronteiriça do Iguaçu (RTI). Doravante, estes projetos serão analisados quanto às suas repercussões territoriais, aos seus objetivos econômicos, políticos e sociais (quando explicitados), aos seus custos e benefícios e à ação ou reação de seus atores nas mais diversas escalas de atuação.

Sobre a área da RTI, definida no Mapa 2, se intercruzam três Eixos de Integração e Desenvolvimento da IIRSA, conhecidos como EIDs. São eles: Capricórnio, Mercosul-Chile e Hidrovia Paraguai-Paraná. Os 13 projetos da IIRSA, identificados na RTI estão distribuídos nos seguintes Eixos: sete em Capricórnio (CAP), três em Mercosul-Chile (MCC) e três em Hidrovia ParaguaiParaná (HPP), conforme Quadro 1.

Dos projetos apontados neste quadro, quatro são do setor rodoviário totalizando aproximadamente 1,2 bilhão de dólares aplicados; dois são do setor ferroviário com 3,3 bilhões de investimento; dois são do setor hidroviário, porém não contém dados de inversão financeira; um é do setor aeroportuário e soma 50 milhões de dólares; três são do setor de energia e apontam a vultuosa soma de 16,7 bilhões de dólares investidos e um é relativo a passo de fronteira com 2 milhões de dólares aplicados. O volume de recursos indica a dimensão das obras e a importância que os países e os setores econômicos emprestam a estes projetos.

Quadro 1 - Projetos da IIRSA Sobre a Área da RTI.

\begin{tabular}{|l|l|l|r|l|}
\hline \multicolumn{2}{|l|}{ PROJETOS DA IIRSA SOBRE A ÁREA DA RTI } & & & \\
\hline Investimentos expressos em milhões de dólares & & & \\
\hline *Linha de transmissão de energia elétrica & & & \\
\hline & & & & \\
\hline EIXO & PROJETO & ESTÁGIO & INVESTIMENTO & PAÍS \\
\hline CAP14 & Nova ponte entre Brasil e Paraguai & Execução & 173,0 & BR-PY \\
\hline CAP18 & Melhoramento rotas N. 2 e N'.7 & Execução & 877,6 & PY \\
\hline CAP19 & Ferrovia Assunção-Ciudad del Este & Projeto & 500,0 & PY \\
\hline CAP67 & LT* Itaipu-Villa Hayes & Concluído & 555,0 & PY \\
\hline CAP26 & Centro de fronteira Puerto Iguazú & Execução & 2,0 & AR \\
\hline CAP29 & Ferrovia Ciudad del Este-Ñeembucú & Pré-execução & $2.800,0$ & PY \\
\hline CAP33 & Melhoramento rota No. 6 & Pré-execução & 136,0 & PY \\
\hline MCC61 & Sistema de Itaipu (existente) & Concluído & $16.000,0$ & BR-PY \\
\hline MCC66 & LT* Itaipu-Londrina-Araraquara & Concluído & 149,1 & BR \\
\hline MCC83 & Aeroporto Guarani & Pré-execução & 50,0 & PY \\
\hline HPP25 & BR-277 - Santa Terezinha-Cascavel & Execução & 4,9 & BR \\
\hline HPP28 & Transposição de Itaipu & Pré-execução & 0,0 & BR-PY \\
\hline HPP29 & Navegabilidade do Lago Itaipu & Concluído & 0,0 & BR-PY \\
\hline
\end{tabular}

Fonte: Carteira de Projetos do COSIPLAN 2017.

Importante observar que, de acordo com o Relatório de Atividades do COSIPLAN de 2017, dos 409 projetos em curso, 63\% são relativos a rodovias e somam apenas $35 \%$ dos recursos de toda a carteira em atividade. Os projetos de energia, por sua vez, retratam apenas $13 \%$ dos projetos, mas representam $27 \%$ dos investimentos. Entretanto, nesta pequena amostragem, dos 13 projetos

ParaOnde!?, Porto Alegre, v.14, n.1, p.71-89, 2020.http://seer.ufrgs.br/paraonde 
que se inserem na RTI, apenas três são referentes a rodovias, o que representa algo em torno de $20 \%$ enquanto constam três projetos de energia, dois de hidrovias e dois de ferrovias, destoando bastante dos percentuais da carteira global. É provável que estas características particulares de composição da carteira de projetos da IIRSA na RTI se expliquem pela presença da empresa Itaipu Binacional e do rio Paraná, o que atrai investimentos para estes setores. A presença de dois projetos em ferrovias pode demonstrar uma clara opção dos atores paraguaios em diversificar sua matriz de transportes em busca de modais mais econômicos.

Embora possam demandar tempo para afetar cadeias produtivas, resultados econômicos ou modos de vida, é possível inferir que os projetos da IIRSA que se situam ou cruzam a área da RTI têm potencial para provocar repercussões territoriais. Em primeiro lugar, pelo volume de recursos aplicados, os quais somam, excluindo-se os 16 bilhões de dólares do sistema existente de Itaipu, outros 5,2 bilhões de dólares, ou ao menos parte deles, que serão investidos nas localidades da Tríplice Fronteira ou em seus arredores, gerando emprego, renda, novas atividades e atraindo novos moradores permanentes. Em segundo lugar, os projetos implicam no surgimento de novos serviços e novas necessidades em termos de equipamentos, estruturas e atividades públicas ou privadas.

Repercussões territoriais podem ser compreendidas como sendo as estruturas territoriais - tais como as redes, os nós estratégicos e as malhas (RAFFESTIN, 1993), além das marcas, das formas, dos produtos, das feições, dos vestígios, do resultado geoeconômico, tais como cadeias produtivas e, das relações de poder territorializadas, resultantes das ações de atores territoriais sobre uma determinada porção do espaço geográfico. Como as ações dos atores territoriais abrangem as mais diversas áreas, escalas e setores, a identificação de suas repercussões territoriais requer recortes de escolha intencional para efeito de análise e aprofundamento.

No setor rodoviário, o acordo para a construção da nova ponte entre Brasil e Paraguai envolve financiamento público oriundo da Empresa Itaipu Binacional. Em recente acordo, os dois países definiram que a seção brasileira da empresa financiará a construção da nova ponte que passará por Porto Meira, no Brasil e Presidente Franco, no Paraguai, enquanto que a fração paraguaia daquela empresa binacional custeará a construção de uma nova ponte entre os dois países conectando as cidades de Carmelo Peralta, no Paraguai e Porto Murtinho, no Estado de Mato Grosso do Sul, Brasil. O ajuste original foi assinado em 2005 e integra o projeto CAP14. Os projetos básico e executivo, elaborados pela empresa VETEC Engenharia Ltda, foram entregues em 2012, ao custo de 3,2 milhões de reais. A licitação foi vencida, em 2014, pelo consórcio Construbase/Cidade/Paulitec. Cada país ficará responsável pelas obras complementares (aduanas) e de acesso, além das desapropriações necessárias. O prazo para a conclusão das obras é 2023.

O Boletim Itaipu Binacional informa, em 11/09/2019, que já estão previstas na região de Porto Meira, a instalação de um "shopping com loja duty free, voltada para lazer e entretenimento, e a instalação da maior roda-gigante da América Latina, com 90 metros de altura". Ainda segundo o informativo, a obra

ParaOnde!?, Porto Alegre, v.14, n.1, p.71-89, 2020.http://seer.ufrgs.br/paraonde 
tem investimento previsto de $\mathrm{R} \$ 463$ milhões, dos quais 323 milhões na construção da ponte e 140 milhões nas obras da Perimetral Leste que ligará a ponte à BR 277, desviando o tráfego de caminhões do centro da cidade, desafogando a Ponte da Amizade e criando assim, melhores condições para o turismo de compras em Ciudad del Este, onde também está projetada uma nova estrada que permitirá seu contorno. No pico das obras se prevê 500 trabalhadores contratados por uma dezena de empresas. A ponte terá 760 metros de comprimento com 470 metros de vão-livre. Diz ainda o boletim que, em 20/05/2020, 20\% das obras já estavam concluídas. No Mapa 3, pode-se observar a localização da nova ponte.

No que lhe diz respeito, as ações de melhoramento nas rotas nacionais $\mathrm{N}^{\circ} 2$ e $\mathrm{N}^{\circ} 7$, integrantes do Projeto CAP18, que ligam Ciudad del Este à Assunção, possibilitarão a realização do percurso em menos tempo e com mais segurança. Esta obra será realizada com recursos privados, mediante a concessão da rodovia ao setor privado por 30 anos, em regime de parceria público-privada (PPP), com data prevista para a conclusão em 2020.

Mapa 3 - Localização da nova ponte com suas respectivas perimetrais nos dois países contornando Foz do Iguaçu e Ciudad del Este.

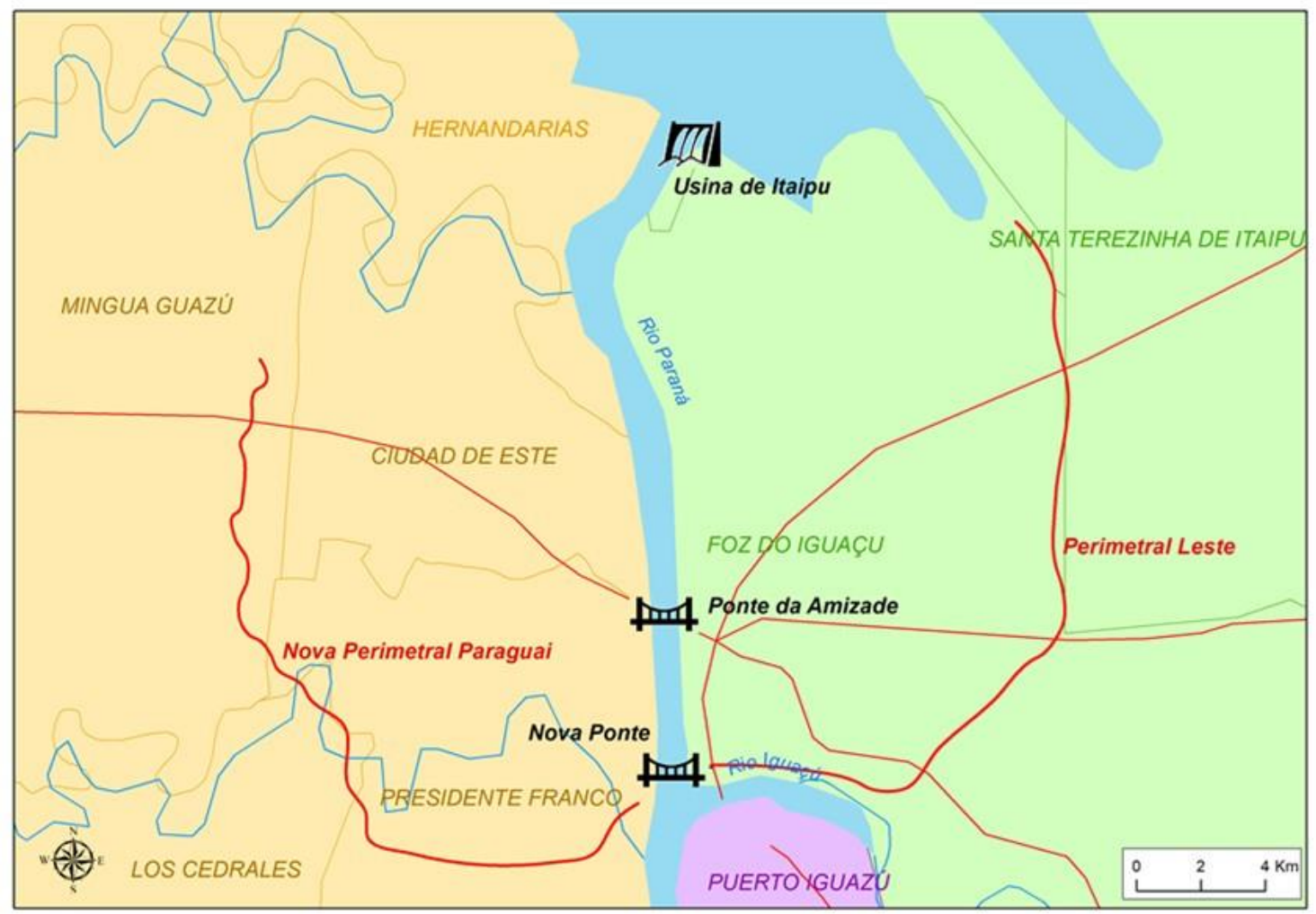

Fonte: Francisco Jorge Vicente, Diagramação, Tito Lívio Barcelos Pereira.

O terceiro projeto rodoviário da IIRSA na RTI refere-se ao melhoramento e concessão da Rota Nacional No 6 (CAP33) que liga a cidade de Encarnación à Rota Nacional $\mathrm{N}^{\circ} 7$, no cruzamento a $30 \mathrm{~km}$ de Ciudad del Este. As obras de reparação estão sendo realizadas com recursos advindos de um financiamento do Banco japonês JBIC e após as melhorias a rodovia será concedida mediante regime de Parceria Público-Privada (PPP). Estas estradas paraguaias terão seu

ParaOnde!?, Porto Alegre, v.14, n.1, p.71-89, 2020.http://seer.ufrgs.br/paraonde 
fluxo incrementado com as obras que estão sendo realizadas por outro projeto no Brasil e que prevê a ampliação da capacidade de transporte BR 277 que liga Santa Terezinha de Itaipu a Cascavel (HPP25). Esta rodovia parte de Paranaguá e se estende até a fronteira, por onde trafegam 11 milhões de veículos/ano, sendo $55 \%$ referentes a transporte de cargas. A operação da rodovia foi concedida ao setor privado pelo prazo de 24 anos, desde 1997, e os recursos para sua ampliação serão também privados. Em 2021 a concessão deverá ser renovada (COSIPLAN - Sistema de Información de Proyectos).

Relativamente ao setor ferroviário existem dois projetos em curso. A Ferrovia Assunção-Ciudad del Este e a Ferrovia Ciudad del Este-Neembucú, sendo que esta última integra o Corredor Ferroviário Bioceânico ParanaguáAntofagasta. A Ferrovia Assunção-Ciudad del Este (CAP19) é ainda uma ideia na medida em que se encontra em estágio de perfil, ou seja, no plano anterior à decisão de fazer, visto que sequer um estudo de pré-factibilidade do projeto foi ainda encomendado. A perspectiva é de que a citada ferrovia, em bitola métrica, ligue Ciudad del Este a Assunção, as duas maiores cidades do Paraguai e transporte tanto carga quanto passageiros, o que certamente impactaria no fluxo e na atividade econômica daquele país.

Este projeto, da Ferrovia Assunção-Ciudad Del Este, prevê interligar a fronteira com o Brasil, em Ciudad del Este e passar pelo Aeroporto Guarani, em Minga Guazú, cidade a $20 \mathrm{~km}$ da fronteira, ao Aeroporto Internacional de Assunção que se localiza em sua região metropolitana, na cidade de Luque, podendo se estender até Villeta, ao sul da capital paraguaia, onde se encontra um grande terminal portuário. Resguardadas as devidas dimensões, seria um projeto que poderia ter uma repercussão territorial semelhante à uma linha férrea com transporte de carga e passageiros entre São Paulo e Rio de Janeiro, no Brasil. A ideia preliminar é de que o projeto tenha financiamento público e custe em torno de meio bilhão de dólares (IDEM).

A Ferrovia Ciudad del Este-Ñeembucú (CAP29), por sua vez, também tem bitola métrica e apresenta outra concepção, mais voltada para o transporte de cereais que embarcariam em portos da Hidrovia Paraguai-Paraná ou seguiriam rumo ao Oceano Pacífico através de uma interconexão com o sistema Ferrocarril Belgrano Cargas, na Argentina, que encontra-se com certa ociosidade. O projeto prevê que a ferrovia passe pelo Aeroporto Guarani e se estenda até a cidade de Pilar, no Departamento de Neembucú, no extremo sudoeste do Paraguai, às margens do rio homônimo, onde está prevista a construção de um porto multimodal. Haveria, entretanto, a necessidade de conclusão, em território brasileiro, do trecho de $150 \mathrm{~km}$ para unir a FERROESTE de Cascavel, no Estado do Paraná, até a fronteira paraguaia, além da construção de duas pontes ferroviárias: uma sobre o rio Paraná, entre Foz do Iguaçu e Ciudad del Este e outra sobre o rio Paraguai entre Ñeembucú, no Paraguai e Puerto Bermejo, na Argentina.

O projeto da Ferrovia Ciudad Del Este-Neembucú contou com a participação técnica da Agência de Cooperação Internacional da Coréia do Sul (KOICA, sigla em inglês) que apresentou, em novembro de 2013, um estudo de factibilidade e um projeto preliminar de engenharia, ao custo de dois milhões de dólares. A ferrovia tem um investimento previsto de 2,8 bilhões de dólares e se

ParaOnde!?, Porto Alegre, v.14, n.1, p.71-89, 2020.http://seer.ufrgs.br/paraonde 
encontra atualmente em gestão de obtenção de recursos e depende do acordo de conexão com o Brasil, embora a fonte de financiamento não esteja ainda definida (IBIDEM).

Relativamente ao setor aeroportuário, a intenção do governo paraguaio com a ampliação e instrumentalização do Aeroporto Guarani, em Minga Guazú, a $20 \mathrm{~km}$ de Ciudad del Este, é transformá-lo em um hub regional de cargas. 0 projeto MCC83 se encontra em fase de pré-execução e após as obras, o aeroporto deverá ser concedido ao setor privado. Os estudos de factibilidade foram custeados pelo tesouro paraguaio, porém as obras, ao custo de 50 milhões de dólares, deverão ter financiamento misto, incluindo recursos públicos, privados e corporativos (COSIPLAN - Sistema de Información de Proyectos).

Quanto ao modal hidroviário, dois projetos da IIRSA se localizam na RTI, o Projeto de Transposição de Itaipu e o de melhoramento da navegabilidade do Lago Itaipu, sendo ambos binacionais, em fase de perfil, ou seja, existem apenas enquanto intenções e ainda não têm nem orçamento nem fonte de financiamento. Relativamente ao primeiro (HPP28), de transposição, de grande magnitude, a ideia é construir ou ampliar portos fluviais a montante e a jusante da represa de Itaipu com sistemas de transbordo de mercadorias do sistema fluvial para caminhões de cargas e vice-versa, de contêineres e cargas a granel, tanto sólidas quanto líquidas, conectados por uma rodovia de grande capacidade de carga. O desenvolvimento da produção de soja e de etanol na Hidrovia Paraná-Tietê poderia tornar o projeto viável em médio prazo, porém as dificuldades são enormes (IDEM).

Já o segundo projeto (HPP29), de melhoramento da navegabilidade do Lago Itaipu, depende da operação da represa até a zona dos Saltos de Guaíra, o que exige uma relação muito ajustada entre o controle de tráfego fluvial e a Itaipu Binacional. O governo brasileiro tem obras previstas com o objetivo de ampliar eclusas e pontes que atualmente restringem o transporte fluvial entre as zonas dos Saltos de Guaíra e o Porto de Conchas sobre o rio Tietê, próximo à cidade de São Paulo. Ainda não existe nenhuma coordenação de Brasil e Paraguai em conjunto com a empresa Itaipu Binacional para monitorar a navegação entre a represa e a zona dos Saltos de Guaíra. Esta ação se realizaria, de forma complementar, ao estudo de viabilidade da transposição da represa de Itaipu, ou seja, vai demandar ainda algum tempo (IBIDEM).

Devido à presença da Usina de Itaipu no espaço geográfico da RTI, os projetos de energia na região ganharam viabilidade e assim, três projetos da IIRSA, se inserem na região da RTI. O primeiro, conforme acima descrito, se trata do sistema de Itaipu e se relaciona com as obras complementares não concluídas e previstas quando da construção da hidrelétrica (MCC61). Os outros dois são linhas de transmissão de energia elétrica que partem da usina, uma em direção ao Paraguai (CAP67), outra em direção ao Brasil (MCC66).

Energia elétrica é um insumo essencial para a vida moderna. A instalação de unidades produtivas e o conforto da vida cotidiana estão a ela relacionados. As ações que visam aumentar a oferta e o acesso da população local e das unidades produtivas locais à energia elétrica, por não visarem tão somente servir de corredores de exportação de commodities, podem fomentar projetos de desenvolvimento regional, de elevação de qualidade de vida e de abertura de

ParaOnde!?, Porto Alegre, v.14, n.1, p.71-89, 2020.http://seer.ufrgs.br/paraonde 
postos de trabalho, dialogando com um processo de integração e coesão do território mais humano e solidário, local e regional, com repercussões benéficas para todas as comunidades circunvizinhas.

A linha de transmissão de 500KV da Itapu Binacional, entre Hernandarias e Villa Hayes (CAP67), próxima à Assunção, começou a ser executada em 2011 e foi concluída em 2013 pelo consórcio ABB/CIE. Além de aumentar a capacidade do sistema elétrico paraguaio, permitindo ao país receber novas indústrias, poderá também acabar com os constantes apagões que ocorrem durante o verão. Trata-se de uma grande contradição, pois apesar de contar com um grande parque gerador, o Paraguai utiliza apenas $10 \%$ da energia de Itaipu. Com esta obra poderá dobrar esta cifra. Esta foi a maior obra do Fundo para a Convergência Estrutural do Mercosul (FOCEM). Ao custo de 320 milhões de dólares, teve, pelo sistema solidário do FOCEM, a maior parte do investimento custeado pelo Brasil.

Em 2014, o Congresso Paraguaio autorizou a contratação de 297 milhões de dólares para a construção da segunda etapa, a linha de transmissão entre Villa Hayes e Ayola, próxima à hidrelétrica de Yaciretá. O projeto básico e os estudos técnicos, econômicos e socioambientais foram conduzidos pela TRACTBEL, multinacional belga, com mais de cinco mil empregados e escritórios em mais de 70 países. A linha foi construída pelo consórcio CIEGEC, formado pela empresa paraguaia, Consórcio de Ingeniería Electromecánica (CIE S.A.) e a africana Somagec Guine Equatorial e inaugurada em 2018. A obra foi financiada pelo Banco Europeu de Investimentos (BEI), pelo Banco Interamericano de Desenvolvimento (BID) e pelo Banco de Desenvolvimento da América Latina (CAF), de acordo com dados do Sistema de Información de Proyectos, do COSIPLAN.

Outro projeto de energia comporta a linha de transmissão de 500KV ligando Itaipu a Araraquara (MCC66), passando por Londrina. Foi licitado em 2003 e concluído dois anos depois ao custo de aproximadamente 150 milhões de dólares, com investimento público e permitiu aumentar a capacidade energética do mercado sudoeste/centro-oeste brasileiro e ligou à Araraquara as conexões que havia entre Itaipu e Ivaiporã, de $750 \mathrm{KV}$ e Ivaiporã a Londrina de 500KV (IDEM). Existe ainda um projeto que prevê a adequação e ampliação da infraestrutura em centros de controle da fronteira entre Brasil e Argentina, em Puerto Iguazú (CAP26), com financiamento público de dois milhões de dólares pelo tesouro argentino.

Estes são os treze projetos, constantes da carteira de projetos da IIRSA, que cruzam ou têm forte interação com a RTI e que estão incrementando a economia, a logística, a infraestrutura e as condições de vida das pessoas que vivem na região. A seguir, ter-se-á como objetivo a caracterização de alguns atores territoriais que operam na RTI.

ParaOnde!?, Porto Alegre, v.14, n.1, p.71-89, 2020.http://seer.ufrgs.br/paraonde 


\section{Transfronteirização e atores territoriais na Região Transfronteiriça do Iguaçu (RTI)}

$\mathrm{Na} \mathrm{RTI}$ pode-se encontrar atores globais, tais como, os bancos que financiam projetos da IIRSA, acima citados, turistas atraídos, principalmente, pelas cataratas e empresas, especialmente de Hong Kong e Miami que trazem seus produtos para serem vendidos nos shoppings e lojas de Ciudad del Este.

Encontra-se também atores com atuação multiníveis, sendo o mais importante deles, a Empresa Itaipu Binacional, a qual, sob o ponto de vista de capacidade de financiamento e de atuação socioespacial, é o maior ator territorial da região, tendo um raio de ação que envolve atividades locais, regionais, nacionais e multinacionais, se constituindo, assim, num protagonista que perpassa as mais diversas densidades de atores territoriais, exercendo múltiplas ações em distintos níveis escalares no âmbito da RTI.

$\mathrm{Na} \mathrm{RTI}$, pode-se observar também a atuação de diversos atores locais e regionais na forma de conselhos formados a partir das três cidades-gêmeas, que possuem estruturas próprias mas que atuam, ora de forma isolada, ora de forma articulada, na busca de seus interesses institucionais particulares mas também, por vezes, na consecução de projetos bi ou tri nacionalmente compartidos.

Assim, temos do lado brasileiro o Conselho de Desenvolvimento Econômico e Social de Foz do Iguaçu (CODEFOZ) criado por lei municipal em 2012 e integrado por mais de uma centena de organizações públicas e privadas. No Paraguai, temos o Consejo de Desarollo de Ciudad del Este (CODELESTE), com dezenas de participantes representando organizações públicas e privadas, acompanhado pela Secretaria Técnica de Planificación del Desarollo Económico e Social, que tem nível ministerial. Na Argentina, encontra-se o Consejo de Desarollo Económico Social y Ambiental de Puerto Iguazú (CODESPI), o qual nasceu como um projeto de cooperação internacional chamado Fronteiras Cooperativas, proposto pelo Serviço de Apoio às Micro e Pequenas Empresas (SEBRAE), do Brasil, com o objetivo de integração econômico-produtiva de Argentina, Brasil e Paraguai em suas áreas de fronteira (SCHLOGEL, 2016).

Cabe ainda mencionar outros atores territoriais que atuam na RTI, como os que sustentam o Programa Oeste em Desenvolvimento, uma articulação regional que opera a cooperação regional, através de uma metodologia de planejamento territorial, entre atores públicos e privados visando o planejamento e a implementação de uma estratégia integrada de desenvolvimento através de um processo participativo. O programa abrange os municípios do oeste do Paraná, contíguos às fronteiras com o Paraguai e a Argentina.

Pode-se citar também o Conselho dos Municípios Lindeiros do Lago de Itaipu, criado em 1990, que agrega 15 municípios da região mais ocidental do Estado do Paraná impactados pela construção de Itaipu, recebendo, ainda hoje, royalties correspondentes.

Numa outra escala de poder e gestão, tem-se ainda o Conselho de Desenvolvimento e Integração do Sul (CODESUL), composto pelos Estados do Rio Grande do Sul, Santa Catarina e Paraná, desde 1961, mais o Mato Grosso do Sul, a partir de 1992, e que prevê em seu Regimento Interno, a inserção da economia regional no processo de integração da América Latina. Tanto o

ParaOnde!?, Porto Alegre, v.14, n.1, p.71-89, 2020.http://seer.ufrgs.br/paraonde 
CODESUL quanto o Conselho dos Municípios Lindeiros do Lago de Itaipu, compuseram a Comissão Permanente para o Desenvolvimento e a Integração da Faixa de Fronteira (CDIF).

Através do Decreto de 8 de setembro de 2010, durante o governo Lula da Silva, foi criada a CDIF, a qual procurou, no âmbito do MERCOSUL construir soluções para adversidades decorrentes da integração, tal como 0 fortalecimento do Programa Integrado de Saúde (SIS Fronteiras), criado em 2005 e que na RTI, permite o atendimento de pacientes oriundos do Paraguai no sistema de saúde brasileiro, mediante documento que ateste sua residência legal no Brasil.

A partir de 2015, com a crise provocada pelas forças de direita no Brasil, que desembocaram no golpe parlamentar contra a Presidenta eleita Dilma Rousseff, as reuniões do CDIF refluíram e diversos programas foram paralisados. O CODESUL e o Conselho dos Municípios Lindeiros do Lago de Itaipu, participaram como membros convidados, de 2010 até a publicação do Decreto 9.961, de 8 de agosto de 2019, do Governo Bolsonaro que revogou o decreto anterior, alterando algumas atribuições da CDIF, eliminando a participação permanente da sociedade civil, além de reduzir de 20 para oito 0 número de ministérios que compõem a referida comissão.

\begin{abstract}
Refletindo a tendência às introspecções nacionais, recentemente, em 2019, novas diretrizes políticas têm sido criadas para as regiões de fronteiras do Brasil baseadas nas teses de defesa, segurança e soberania nacional com a recriação do Comissão Permanente para 0 Desenvolvimento e a Integração da Faixa de Fronteira e a criação dos centros integrados de segurança, com a coordenação diretamente ligada ao Gabinete de Segurança Institucional da Presidência da República (GSI). O primeiro centro integrado deverá ser instalado em Foz do Iguaçu o que deverá reforçar a dimensão estratégica de defesa da Região Transfronteiriça do Iguaçu (RÜCKERT, 2019, p.10-11).
\end{abstract}

Em paralelo a estes atores, encontramos atuando na RTI, alguns que têm ligação direta com o MERCOSUL, tais como, o Projeto MERCOCIDADDES (do qual Foz do Iguaçu faz parte, mas Ciudad del Este e Puerto Iguazú, não), o Grupo de Trabalho sobre Integração Fronteiriça e o Foro Consultivo de Municípios, Estados Federados, Províncias e Departamentos (FCCR), além dos projetos surgidos de acordos bilaterais, como a Escola Intercultural Bilingue e a UNILA, e ainda, acordos de facilitação turística e de localidades fronteiriças vinculadas (SCHLOGEL, 2016).

Em cooperação com a UE, o INNOVACT II iniciou ações em março de 2019 para implantação de suas diretrizes e assessorias na região transfronteiriça do Iguaçu, na Bacia do Prata, focando, principalmente, no meio ambiente e no turismo. Entretanto, a coordenação do referido projeto na América Latina reconhece que existem grandes disparidades entre as condições institucionais e legais da cooperação fronteiriça na UE e no subcontinente, as quais deveriam "sofrer alterações" para permitir ações entre atores econômicos dos três países, conforme informou a Diretora para a América Latina, Silke Haarich, no evento Open Days of Regions and Cities, em 9 de outubro de 2019, em Bruxelas.

Há um certo grau de ação conjunta em busca de solução de problemas ligados ao turismo, ao narcotráfico, ao desenvolvimento, à educação, à saúde e

ParaOnde!?, Porto Alegre, v.14, n.1, p.71-89, 2020.http://seer.ufrgs.br/paraonde 
a outros temas que envolvem estes conselhos, porém, de maneira quase informal, com baixo nível de institucionalidade. São iniciativas voluntárias e quase sem apoio governamental, mas que mantém viva a ideia de construção e desenvolvimento de regiões transfronteiriças, embora de forma muito lenta e desarticulada.

SCHLOGEL (2016, p.16-17) avalia que "a construção de um projeto de sociedade integracionista, ou não, depende das correlações de força que se apresentam". Ainda afirma que: "o fortalecimento do MERCOSUL nos últimos anos é em grande parte responsável pelo fortalecimento das conexões estabelecidas na região trinacional do Iguaçu".

Os protagonistas acima relacionados, bancos e instituições que financiam os projetos, empresas de construção que executam as obras, organizações da sociedade civil e entes federativos nas mais diversas escalas, dentre outros, constituem a plêiade de atores territoriais que atuam em projetos da IIRSA na $\mathrm{RTI}$. Esta profusão de agentes, conexões, interesses, projetos, recursos e gestão de poder, nas mais distintas escalas geográficas, está criando condições profícuas para a consolidação de uma autêntica região transfronteiriça no coração da Bacia do Prata, mais especificamente, na Tríplice Fronteira entre Argentina, Brasil e Paraguai.

\section{Considerações finais}

$\mathrm{Na}$ atualidade, as fronteiras são mais bem compreendidas quando se leva em conta as relações e os processos que se desenvolvem em seu entorno, tais como, os processos de transfronteirizações.

Em pleno coração da Bacia do Prata está se conformando uma região transfronteiriça no entorno da Tríplice Fronteira, envolvendo cidades gêmeas de três países diferentes. Esta afirmação é possível porque a RTI já apresenta atributos considerados para se definir região transfronteiriça na Europa, embora não seja objetivo deste artigo, aprofundar este debate. A falta de normatização na América do Sul em relação a este fenômeno territorial não impede seu desenvolvimento, porém inibe e atrasa ações governamentais que poderiam acelerar seu processo de conformação institucional, de maneira concreta e visível. Em outras áreas de fronteiras na América do Sul, já é possível se observar princípios destes eventos territoriais, embora com ritmos e escalas distintas.

A forte intensidade regular e cotidiana de relações interpessoais, familiares, institucionais, formais ou informais, somada aos fluxos econômicos, logísticos e financeiros presente na RTI corroboram a afirmação acima. A construção da Ponte da Amizade, em 1965 e a construção da Itaipu Binacional, em 1984, intensificaram estes processos que já se manifestavam pela atração turística das cataratas e pelas condições de compras de mercadorias mais baratas em Ciudad del Este.

As ações da IIRSA na RTI, em especial a construção da nova ponte entre Brasil e Paraguai, podem dinamizar ainda mais este fenômeno, além de outras ações, tais como, a maior oferta de energia, estradas e ferrovias. Nota-se, entretanto, uma clara tendência nas ações da IIRSA com a prioridade para o escoamento da produção de commodities através de corredores de exportação,

ParaOnde!?, Porto Alegre, v.14, n.1, p.71-89, 2020.http://seer.ufrgs.br/paraonde 
sem se deter, ao menos na RTI, com ações que promovam o desenvolvimento regional, com a consequente retenção de recursos, tecnologias e ocupações produtivas que fortaleçam a economia local e aufiram ganhos permanentes aos trabalhadores e aos setores mais pobres da população local. Mais uma vez, quem serão beneficiados serão os grandes capitais nacionais e/ou multinacionais. Em mais uma experiência histórica, o capital vai moldando o território aos seus interesses de acumulação.

A Academia tem como uma de suas tarefas, analisar os alicerces que fundamentam os conceitos, bem como os atributos que animam os fenômenos denominados regiões transfronteiriças e propor que os poderes constituídos criem feições institucionais adequadas que as regulamentem para permitir e fomentar o desenvolvimento harmônico e sustentado destas novas regiões que, apesar, da pouca habilidade de governos e Estados, teimam em se manifestar e se constituir, de fato.

\section{Referências}

AMILHAT SZARY, A. e GIRAUT, F. Borderities: The politics of contemporary mobile borders. ResearchGate, 2015.2 Disponível em <www.researchgate.net/publication/304879946>. Acesso em 15/08/2019.

BALIBAR, E. Qu'est-ce qu'une Frontière? In BALIBAR, E. La crainte des massses. Politique et philosophie avant et après Marx. Paris: Galilée, 1996.

BENEDETTI, A. La plata region tripoints; state of the matter and descriptive comparison. In CARGNIN, A. P., RÜCKERT, A. A. e LEMOS, B. O. (Eds). Territorial planning and la Plata Basin borders. Porto Alegre: Editora Letra1, 2018, pp. 81-110.

CAMPOS, H. A. O papel estratégico de cidades gêmeas no controle de mercadorias em regiões de fronteira no contexto do MERCOSUL: Uruguaiana (BR) e Paso de los Libres (AR). Redes - Santa Cruz do Sul: Universidade de Santa Cruz do Sul (UNISC), v. 22, n. 1, jan-abr - 2017.

CARNEIRO FILHO, C. P. Processos de transfronteirização na Bacia do Prata. A Tríplice Fronteira Brasil-Argentina-Paraguai. Tese (Doutorado em Geografia) Programa de Pós- Graduação em Geografia, Universidade Federal do Rio Grande do Sul, Porto Alegre, p. 254, 2013.

CODEFOZ. Conselho de Desenvolvimento Econômico e Social de Foz do Iguaçu. Sítio Oficial. Disponível em <www.codefoz.org.br $>$. Acesso em 14.09.2019.

COSIPLAN. Sistema de información de proyectos - IIRSA/COSIPLAN. Disponível em <www.cosiplan.org/proyectos>. Acesso em 13/08/2019.

FRANÇA da Silva Junior, R. As três dimensões da fronteira entre Brasil, Paraguai e Argentina: Proposta de análise para pensar a integração in BENVENUTO, J. Somos todos irmãos? Reflexões sobre a percepção da integração regional na fronteira do Brasil, Argentina e Paraguai. Foz do Iguaçu, Puerto Iguazú, Ciudad del Este: GEDAI, 2016, pp. 117-152.

ITAIPU BINACIONAL. Sala de Imprensa. Sítio Oficial. Disponível em: <https://www.itaipu.gov.br/sala-de-imprensa>. Acesso em 19.09.2019.

ParaOnde!?, Porto Alegre, v.14, n.1, p.71-89, 2020.http://seer.ufrgs.br/paraonde 
MACHADO, L. O. Limites, Fronteiras, Redes in STROHAEKER, T. M., DAMIANI, A., SCHAFFER, N. O. BAUTH, N. e DUTRA, V. S. (org). Fronteiras e espaço global. Porto Alegre: AGB-Porto Alegre, 1998, pp. 41-49.

MACHADO, L. O. Cidades na Fronteira Internacional: Conceitos e Tipologia. In: NUÑES, A., PADOIN, M. M. e OLIVEIRA, T. C. M. Dilemas e diálogos platinos. Fronteiras. Dourados: Editora UFGD, 2010, pp. 57-72.

OESTE EM DESENVOLVIMENTO. Estudo energético regional do oeste paranaense. Sítio Oficial. Disponível em $<$ www.oesteemdesenvolvimento.com.br>. Acesso em 18.09.2019.

PAIVA, C. A. Plano de desenvolvimento econômico de Foz do Iguaçu Diagnóstico. Foz do Iguaçu: Latus Consultoria, Prefeitura Municipal de Foz do Iguaçu e CODEFOZ, 2014.

RAPPOPORT, M. e MADRID, E. Os Países do Cone Sul e as grandes potências. In CERVO, A. L. e RAPPOPORT, M. (Orgs). História do Cone Sul. Rio de Janeiro e Brasília: Editora Revan e Editora UNB, 1998, capítulo V, pp. 239-288.

REVISTA EXAME. Especialistas estudarão viabilidade na eclusa de Itaipu. Economia. Disponível em <https://exame.abril.com.br/economia/especialistasestudarao-viabilidade-de-eclusa-na-usina-de-itaipu/>. Acesso em 13.06.2019.

RÜCKERT, A. A. Políticas territoriais em cenários de incertezas. Securitização das fronteiras em regiões transfronteiriças na Bacia do Prata, América do Sul. (Não publicado), 2019.

RÜCKERT, A. A, CAMPOS, H. A, SUPERTI, E. e PORTO, J. L. R. Transfronteirizações na América do Sul: uma agenda de pesquisa sobre dinâmicas territoriais nas fronteiras meridional e setentrional do Brasil. Revista Eletrônica de Humanidades do Curso de Ciências Sociais da UNIFAP. Macapá, 2014. Disponível em: <http://periodicos.unifap.br/index.php/pracs>. Acesso em 02/07/2019.

SCHLOGEL, D. A. A influência do MERCOSUL na região trinacional do Iguaçu. Dissertação (Mestrado em Integração Contemporânea da América Latina) Programa de Pós-Graduação em Integração Contemporânea da América Latina, Universidade Federal da Integração Latino-Americana. Foz do Iguaçu, p. 119, 2016.

VICENTE, F. J. Dimensão social em processos de integração regional: aspectos teóricos e o caso do MERCOSUL. Dissertação (Mestrado em Estudos Estratégicos Internacionais) - Programa de Pós-graduação em Estudos Estratégicos Internacionais, Universidade Federal do Rio Grande do Sul. Porto Alegre, p. 256, 2015.

WASSENBERG, B. e REITEL, B. Territorial cooperation in Europe. A historical perspective. Luxembourg: European Union, 2015.

ParaOnde!?, Porto Alegre, v.14, n.1, p.71-89, 2020.http://seer.ufrgs.br/paraonde 